\title{
Autosomal dominant limb-girdle muscular dystrophy type 1C
}

INSERM

\section{Source}

INSERM. (1999). Orphanet: an online rare disease and orphan drug data base. Autosomal dominant limb-girdle muscular dystrophy type 1C. ORPHA:265

Autosomal dominant limb-girdle muscular dystrophy type 1C (LGMD1C) is a subtype of autosomal dominant limb girdle muscular dystrophy characterized by a childhood to adulthood onset of progressive, mild-to-moderate proximal muscle weakness, calf hypertrophy, and variable muscle cramping/stiffness or myalgia, after exercise. A positive Gowers sign and elevated creatine kinase serum levels are frequently observed. Initial motor milestones are usually normal and muscle rippling may be observed. Respiratory and cardiac anomalies are generally not associated with LGMD1C. 